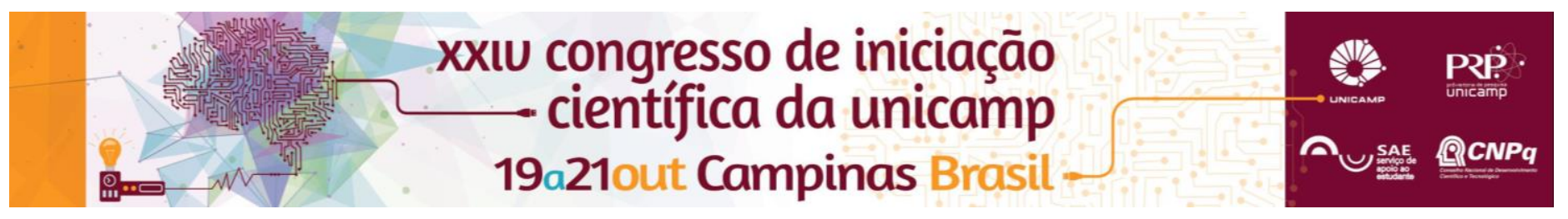

\title{
Defesas químicas na mariposa Syntomeida melanthus (Erebidae: Arctiinae)
}

\author{
Isabela Aparecida Oliveira Lima*, Diomar Verçosa, José Roberto Trigo
}

\section{Resumo}

A mariposa Syntomeida melanthus (Arctiinae: Erebidae) apresenta uma coloração conspícua tanto na fase larval quanto como adulto. Levantamos a hipótese que essa espécie é defendida quimicamente devido ao sequestro de compostos químicos de folhas de sua planta hospedeira Ipomoea carnea fistulosa (Convolvulaceae). Testamos essa hipótese usando como predadores a aranha Lycosa erythrognatha e a ave Gallus gallus. Os resultados preliminares indicam que Syntomeida melanthus é defendida contra esses predadores e também sequestra swainsonina, um alcaloide indolizidínico, da sua planta hospedeira.

\section{Palavras-chave}

alcaloides indolizidínicos, predação, swainsonina

\section{Introdução}

Uma das formas pela qual um animal pode recorrer para evitar a predação é a defesa química, comum em insetos fitófagos. Geralmente esses insetos sequestram compostos químicos de suas plantas hospedeiras e essas substâncias conferem proteção química contra predadores, tornado os insetos impalatáveis.

A mariposa Syntomeida melanthus (Arctiinae: Erebidae) apresenta uma coloração conspícua tanto na fase larval quanto como em adultos. Levantamos a hipótese que essa espécie é defendida quimicamente devido ao sequestro de compostos químicos de folhas de sua planta hospedeira Ipomoea carnea fistulosa (Convolvulaceae). Testamos essa hipótese em larvas de $S$. melanthus usando como predadores a aranha-dejardim Lycosa erythrognatha e a ave Gallus gallus, e larvas do besouro Tenebrio molitor como um inseto controle palatável. Esperamos que as larvas de $S$. melanthus sejam predadas em uma menor percentagem do que as larvas palatáveis de $T$. molitor.

\section{Resultados e Discussão}

Em relação a predação pela aranha $L$. erythroghnatha, as larvas de $S$. melanthus $(n=12)$ foram significativamente menos predadas do que as larvas palatáveis de T. molitor (Figura 1A).

Quando usamos indivíduos jovens de G. gallus como predador, estes não tocavam ou bicavam e liberavam as larvas de $S$. melanthus $(n=12)$ (Figura 1B). Essas larvas sobreviviam até empuparem. Entretanto $G$. gallus predou todos os indivíduos palatáveis de $T$. molitor (Figura 1B).

Quando analisados por cromatografia liquida de alto desempenho-espectrometria de massas, tanto larvas, quanto pupas e adultos de ambos os sexos de $S$. melanthus apresentaram o alcaloide indolizidínico swainsonina em seus tecidos.
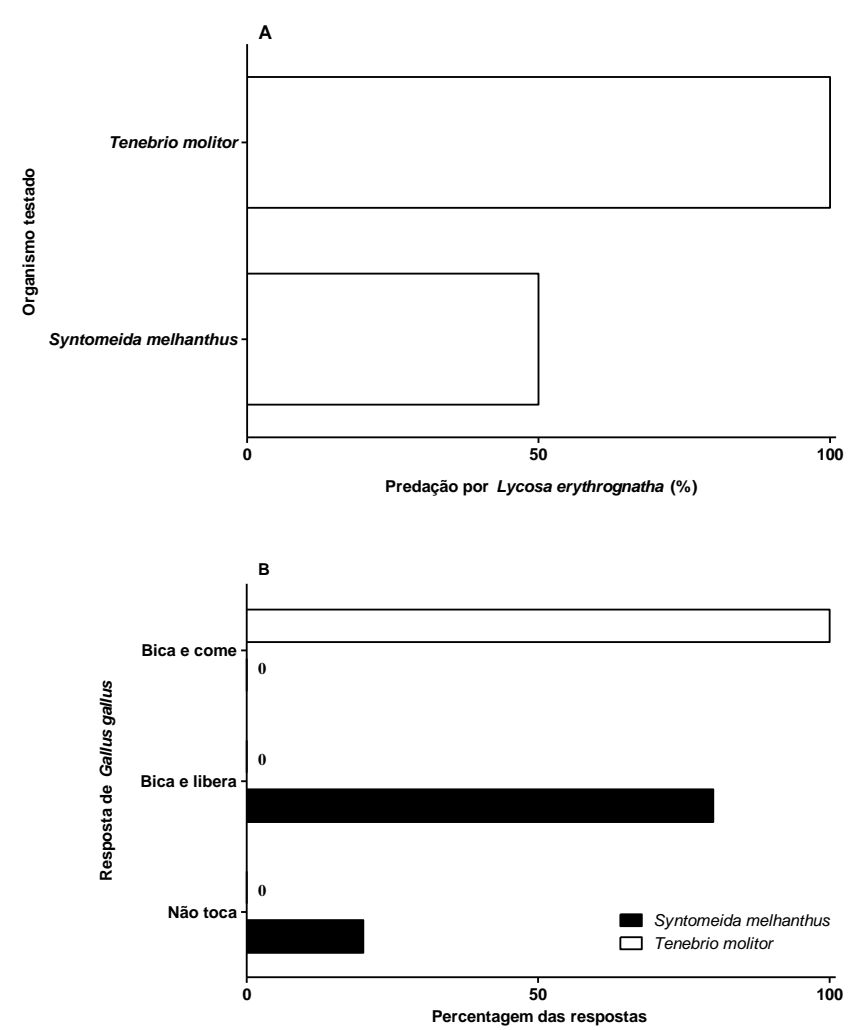

Figura 1. Bioesaios de predação em larvas de Syntomeida melanthus com os predadores (A) a aranha Lycosa erythrognatha e (B) a ave Gallus gallus.

\section{Conclusões}

Nossos resultados indicam que Syntomeida melanthus é defendida contra predação, provavelmente devido ao alcaloide indolizidínico swainsonina, que é sequestrado da planta hospedeira Ipomoea carnea fistulosa.

\section{Agradecimentos}

Agradecemos a FAPESP (2011/17708-0) e CNPq (306103/2013-3) pelo apoio financeiro. 